\title{
MANTRA PENGOBATAN DALAM UPACARA PENYEMBUHAN TERHADAP KARAKTERISTIK MASYARAKAT LEBAK - BANTEN
}

\author{
DINI FITRIANI \\ Dosen STKIP Kusuma Negara Jakarta \\ dinifitriani@stkipkusumanegara.ac.id
}

\begin{abstract}
ABSTRAK
Mantra adalah salah satu jenis wacana tulis dan lisan, sebab mantra bisa digunakan diberbagai konteks atau kebutuhan sesuai dengan sudut pandang yang akan digunakan. Bentuk mantra biasanya secara tertulis, namun cara penggunaan mantra biasanya berbentuk lisan, dalam mantra terdapat isi atau makna yang terkandung untuk suatu hal yang mengenai kepentingan pribadi(sakral). Mantra yang dimaksud oleh peneliti adalah mantra untuk pengobatan. Mantra pengobatan adalah salah satu budaya yang saat ini masih digunakan bahkan di lestarikan oleh masyarakatnya, terutama pada masyarakat di Kampung Cicadas, Desa Sudamanik, Kecamatan Cimarga, Kabupaten Lebak-Banten. Kepercayaan terhadap mantra pengobatan tersebut dapat menngambarkan karakteristik masyrakat akan kebiasaan atau budaya dalam pengobatan suatu penyakit. Dengan adanya mantra pengobatan pada lingkungan masyarakat tersebut, pada setiap mengobati suatu enyakit masyarakan lebih mendahulukan pengobatan kepada orang yang biasa mengobati dengan mantra.
\end{abstract}

Kata Kunci: Mantra Pengobatan, Upacara Penyembuhan, Karakteristik Masyarakat

\section{PENDAHULUAN}

Masyarakat Indonesia telah bersifat magis. Magis berarti sesuatu yang mengenal mantra sejak dulu. Mantra dipakai manusia untuk mencapai dikenal masyarakat Indonesia sebagai tujuannya dengan cara-cara yang rapalan „ucapan dalam bahasa tertentue ${ }^{\text {ee }}$ istimewa. Perilaku magis disebut juga untuk maksud dan tujuan tertentu (maksud sebagai perilaku yang dilakukan untuk baik maupun maksud kurang baik). mencapai suatu maksud tertentu yang 
FON ; Jurnal Pendidikan Bahasa dan Sastra Indonesia

Volume 12 Nomor 1 Tahun 2018

dipercaya manusia ada di alam

naratif pun dapat dianggap sastra lisan, supranatural (Rusyana, 1970: 3). ${ }^{1}$ Menurut misalnya lagu-lagu, teks humor, teka-teki, Semi (1993:3), sastra lisan yang terdapat pada masyarakat suku bangsa Indonesia sudah lama ada. Bahkan setelah tradisi tulis berkembang, sastra lisan masih dijumpai juga, baik dari segi kualitas maupun dari segi kuantitas. ${ }^{2}$ Sastra lisan di Indonesia luar biasa kayanya dan luar biasa ragamnya. Melalui sastra lisan, masyarakat dengan kreativitas yang tinggi menyatakan diri dengan menggunakan bahasa yang artistik, bahkan pada saat sekarangpun masih dijumpai tradisi lisan terutama digelarkan dalam upacaraupacara adat.

Dalam dunia sastra, mantra adalah salah satu bentuk sastra lisan yaitu puisi rakyat, kalimatnya tidak berbentuk bebas melainkan berbentuk terikat (Danandjaja, 1984: 46). ${ }^{3}$ Lebih lanjut, Zaimar (dalam Pudentia, 2008: 221) menyatakan bahwa "berbagai teks lisan yang tidak bersifat

\footnotetext{
${ }^{1}$ Rusyana, Y,. Berbagai Puisi Mantra Sunda.( Laporan Penelitian Bandung:Proyek Penelitian Pantun dan Folkar,1970), hlm.3.
} dan jampi-jampi dukun”. Mantra dikategorikan sebagai sastra lisan karena berupa puisi magis yang dimiliki oleh masyarakat yang diperoleh dan disebarkan secara lisan. ${ }^{4}$

Hal lain juga dikatakan bahwa “ Poems are beautiful words (folk poetry) having regularity (Yuwono, 2007: 10). Poem is very inherent in the folklore of the Indonesian people, especially traditional Malay society. Poem always becomes the part of the customary expression of traditional societies in various events of tradition, such as in a traditional wedding ceremony, traditional feast, the award customary title, and various events of folk entertainment ${ }^{, 5}$ Puisi adalah kata-kata indah (puisi rakyat) yang memiliki keteraturan (Yuwono, 2007: 10).

Pembacaan mantra sebagai salah satu kegiatan yang bersifat religius dan sakral yang memiliki syarat dan cara tertentu yang dilakukan agar tujuan tercapai. Semua syarat-syarat dan cara

${ }^{2}$ Semi, Atar. Metode Penelitian Sastra. Bandung:

Angkasa Bandung. 1993), hlm. 3.

\footnotetext{
${ }^{4}$ Pudentia, MPSS (Ed.), Metodologi Kajian Sastra Lisan. (Jakarta: Asosiasi Tradisi Lisan.2008), hlm. 221.

${ }^{5}$ Yuwono, Untung. (2007). Gerbang Sastra Indonesia Klasik. International Journal of Language Education and Culture Review, 2015, Vol. 1, No. 1, 31-40
}

${ }^{3}$ Danadibrata, R.A. Kamus Basa Sunda. 
FON ; Jurnal Pendidikan Bahasa dan Sastra Indonesia

Volume 12 Nomor 1 Tahun 2018

tersebut merupakan aspek pendukung yang ada di kampung Cicadas, desa pembacaan mantra yang telah ditetapkan Sudamaik, kecamatan Cimarga Lebakoleh dukun atau pawang tersebut. Menurut Soedjijono (1987:91) terdapat beberapa persyaratan dalam membacakan mantra sebagai berikut, waktu, tempat, peristiwa atau kesempatan, pelaku, perlengkapan, pakaian dan cara membawakan mantra. ${ }^{6}$

Ada 15 mantra pengobatan yang masih sering di gunakan oleh masyarakatnya. Tepatnya, di Kampung Cicadas, Desa Sudamanik, Kecamatan Cimarga, Lebak-Bnten. Mantra-mantra pengobatan ini di percaya sebagai salah satu mantra pengobatan yang sangat ampuhterhadap khasiatnya, bahakan masih banyak yang menghiraukan pengobatan medis karna adanya mantramantra ini, dan dari 15 mantra ini mempunyai fungsi atau khasiat yang berbeda-beda dalam pengobatanya. Mantra pengobatan ini didapat dari orangorang (sesepuh), mantra mantra ini hanya bisa dilakuakn oleh orang orang yang mempunyai ilmu atau tata cara dalam pengobatanya, terutama pada sesepuh

\footnotetext{
${ }^{6}$ Soedjijino, dkk. Struktur dan Isi Mantra Bahasa Jawa di Jawa Timur. (Jakarta:Departemen Pendidikan dan Kebudayaan. 1987),hlm. 91.
}

\section{Banten.}

Berikut adalah 15 mantra pengobatan yang masih digunakan di Kampung Cicadas, Desa Sudamanik, Kecamatan Cimarga, Lebak-Banten, yaitu:

1. Mantra pengobatan untuk Lieur Sirah Sabelah

2. Mantra pengobatan untuk Siwurungan

3. Mantra pengobatan untuk singsireuman

4. Mantra pengobatan untuk Panas Tinggi

5. Mantra Pengobatan untukNyeuri Ceuli

6. Mantra Pengobatan untuk Kasengat panon Poe

7. Mantra Pengobatan untuk Mimisan

8. Mantra Pengobatan untuk ngalancarken ker lahiran

9. Mantra Pengobatan untuk

\section{Kejengkolan}

10. Mantra Pengobtan untuk Ka gores benda seuket

11. Mantra Pengobatan untukCacingan

12. Mantra Pengobatan untuSirep IdemIdem (Panas)

13. Mantra Pengobatanuntuk Nyeri Dada 
FON ; Jurnal Pendidikan Bahasa dan Sastra Indonesia

Volume 12 Nomor 1 Tahun 2018

14. Mantra pengobatann untuk Nyeri dari satu kalimat dengan kalimat lainya sirah

\section{Mantra Pengobatan untuk Aratel}

\section{PEMBAHASAN}

Penelitian ini bertujuan untuk mengetahui karakter masayarakat setempat yang biasa menggunakan mantra pengobatan pada suatu penyembuhan penyakit tertentu pada mayarakat kampung Cicadas, Lebak-Banten .Berdasarkan tujuan tersebut, maka metode yang digunakan dalam penelitian ini menggunakan penelitian deskriptif kualitatif.

Pada penelitian ini data yang diperoleh berupa wacana tulis yang berbentuk ujaran atau tuturan dalam Wacana Mantra Pengobatan yang berada di kampung Cicadas, Desa Sudamanik, Kecamatan Cimarga, Kabupaten Lebak-Banten.

Mengenai 15 wacana mantra pengobatanDi kampung Cicadas, Desa Sudamanik, Kecamatan Cimarga, Kabupaten Lebak-Banten ini sering kali di sangkut pautkan dengan tumbuhan atau tanaman sebagai salah satu bahan ramuan atau sesajen untuk pelengkapdalam pengobatan atau ritualnya.

Mantra pengobatan ini merupakan wacana mantra tulis yang menghubungkan yang sehingga di dalamnya mempunyai arti dan makna mengenai unsur magis yang di percaya mampu mengobati berbagai penyakit dan didalam kalimat tesebut mempunayai arti atau makna yang meminta kepada sang penciptaNya untuk kesembuhan dalam suatu penyakit yang di deritanya.

Lima belas wacana mantra pengobatan yang berasal dari Kampung Cicadas, Desa Sudamanik, Kecamatan Cimarga, Kabupaen Lebak-Banten yang peneliti teliti bahwa dalam upacara penyembuhan suatu penyakit masyarakat tersebut memang berdasarkan informasi banyak menghasilkan hasil yang baik, artinya melalu mantra pengobatan ini masyarakat banyak mengalami kesembuhan, karena seperti yang diterangkan sebelumnya, bahwa mantra pengobatan ini mengandung unsure do'a, dimana meminta kepada yang kuasa dengan menggunakan suatu bahan atau material missal buah berenuk untuk suatu penyembuhan tertentu. Jadi ada suatu alat perantara material tradisioal yang dikombinasikan dengan mantra tersebut, dan aspek mistis yang terdapat pada mantra pengobatan tersebut. Karena sebab itulah masyarakat Kp. Cicadas di Kabupaten Lebak banten tersebut ketika 
mereka sakit pertama kali yang dituju untuk menyembuhkan penyakit adalah sesepuh kampong tersebut yang memang betul-betul menguasail mantra pengobatan tersebut. Mereka lebih percaya kepada mantra pengobatan tersebut dibandingkan dengan pengobatan medis. Adapun untuk pengobatan medis mereka anggap sebagai penyempurna pengobatan saja.

\section{PENUTUP}

Sesuai uraian penelitian di atas maka penulis dapat menarik simpulan bahwa mantra pegobatan yang berada di kampung Cicadas, desa Sudamanik, kecamatan Cimarga, Kapupaten LebakBanten dalam aspek upacara penyembuhan menggunakan ritual do'a sederhana, yang kebanyakan menghasilkan energy yang positif bagi penyembuhan masyarakat tersebut sehingga mampu mencerminkan sikap masyarakat yang percaya akan kemampuan mantra tersebut dalam menyembuhkan suatu penyakit, sehingga mereka sering pergi ke sesepuh setempat apabila mempunyai suatu penyakit untuk berobat dengan menggunakan mantra atau yang biasa masyarakat setempat sebut dengan rajah.
Berdasarkan simpulan di atas, peneliti memiliki saran, yaitu, saran yang pertama adalah masyarakat seyogianya tidak mempunyai anggapan yang negatif pada mantra-mantra, khususnya pada mantra pengobatan dari Kabupaten LebakBanten. Melalui mantra-mantra yang hakikatnya adalah doa, masyarakat diharapkan lebih dekat kepada sang penciptaNya ialah Allah. Mayarakat dapat memanfaatkan mantra-mantra pengobatan yang bijak agar tidak mengarah pada kemusyrikan. Dan tabib yang memiliki mantra-mantra pengobatan tersebut, diharapkan dapat mewarisi ilmunya kepada anak-cucu atau orang yang ia percayai untuk memberikan ilmu mantranya. Saran kedua adalah berobat secara medis ataupun non medis boleh dilakukan karena sang penyembuh hanya sang Maha Kuasa Allah SWT.

\section{DAFTAR PUSTAKA}

Bungin, Burhan. 2007. Metode

Penelitian: Komuniksi, Ekonomi, Kebujakan Publik, dan Ilmu Sosial lainya. Jakarta: Kencana. Danadibrata, R.A. 2009. Kamus Basa Sunda. Bandung: PT Kiblat Buku Utama. 
FON ; Jurnal Pendidikan Bahasa dan Sastra Indonesia

Volume 12 Nomor 1 Tahun 2018

Djamaris, Edwar. 1990.Menggali

Khazanah Sastra Melayu Klasik

(Sastra Indonesia Lama). Jakarta:

Balai Pustaka.

Pudentia, MPSS (Ed.. 2008. Metodologi

Kajian Sastra Lisan. (akarta:

Asosiasi Tradisi Lisan.

Rusyana, Y, 1970. Berbagai Puisi Mantra

Sunda. Laporan Penelitian

Bandung:Proyek Penelitian Pantun dan Folkar.

Semi, Atar. 1993. Metode Penelitian

Sastra. Bandung: Angkasa

Bandung.

Sugiono. 2009. Metode Penelitian,

Pendekatan Kuantitatif, Kualitatif

dan $R \& D$. Bandung: Alfa Beta.
Soedjijino, dkk. 1987. Struktur dan Isi

Mantra Bahasa Jawa di Jawa

Timur. Jakarta:Departemen

Pendidikan dan Kebudayaan.

Teeuw. 1984. Sastra dan ilmu sastra.

Bandung: Pustaka Jaya.

Yuwono, Untung. Gerbang Sastra

Indonesia Klasik. Jakarta:

Wedatama Widya Sastra, 2007.

Yuwono, Untung. (2007). Gerbang Sastra Indonesia Klasik. International

Journal of Language Education and

Culture Review, 2015, Vol. 1, No. 1, $31-40$

Zaidan, Abdul Razak. 2004. Kamus Istilah Sastra. Jakarta: Balai Pustaka. 